An.ESALQ, Piracicaba, 45(parte 2):463-478, 1988

\title{
ACEITABILIDADE DO SABOR DO IOGURTE DE "LEITE DE SOJA" ADICIONADO DE LEITE DE VACA EM VARIOS SABORES*
}

G. de Souza**

A.J. de Oliveira***

I. Shirose*t**

RESUMO: Estudou-se, neste trabalho, a aceitabilidade do sabor do iogurte de "leite de soja" adicionado de leite de vaca em vários sabores, nos teores de $85 \%$ de "leite de soja" e $15 \%$ de leite de vaca.

Todos os dez saborizantes experimentados propor cionaram ao produto sabor aceitável e no grau de aceita= bilidade "gostei regularmente".

Termos para indexação: Iogurte com frutas, "1eite de soja".

\section{ACCEPTABILITY OF THE FLAVOR OF SOYBEAN \\ MILK IOGHURT ADDED OF COW'S MILK IN SEVERAL FLAVORS}

* Parte da dissertação de Mestrado apresentada pelo primeiro autor à E.S.A. "Luiz de Queiroz" da Universidade de São Paulo em 1986 e financiada :pelo CNPq.

* Seção de Leite e Derivados do Instituto de Tecnologia de Alimentos - ITAL, 13073 - Campinas - SP.

*** Departamento de Tecnologia Rural da E.S.A. "Luiz de Queiroz" da Universidade de São Paulo - 13400 - Piracicaba - SP.

**** Seção de Estatística do Instituto de Tecnologia de Alimentos - ITAL - 13073 - Campinas - SP. 
464 An.ESALQ, (Piracicaba, 45(parte 2):463-478, 1988

ABSTRACT: A study was made of the acceptability of the flavor of soybean milk ioghurt, to which $15 \%$ of cow's milk in several flavors was added.

All the ten experimented flavors gane the product aceptable flavors, at the "liked regularly" acceptability degree of the hedonic scale.

Index terms: Fruit ioghurt, soybean milk.

\section{INTRODUÇAO}

A fermentação láctica do "leite de soja" pelas bac térias do iogurte, tais como streptococcus thermophilus e Lactobacizzus buzgaricus mais adição de frutas, essências e açúcar an fermentado, é um método simples e não dispendioso de se melhorar ou mascarar o gosto indesejável residual da soja no produto e, consequentemente, de se obter uma bebida fermentada muito saudavel, de caracteristicas semelhantes ao iogurte tradicional. (PINTHONG et alii, 1980). Segundo KANDA et alii(1976), KOPSIC \& LAURIC (1978), o iogurte de "leite de soja" com frutas é um produto perfeitamente aceitável e que tem a sua produção comercial altamente favorecida pelo fato dos consumidores já estarem habituados ao iogurte tradicional com frutas.

SOUZA et alii (1988) estudaram a aceitabilidade do sabor de iogurte de "leite de soja" adicionado de leite de vaca e chegaram à conclusão de que se pode utilizar atē $85 \%$ de "leite de soja" na formulação do produto.

o objetivo do presente trabalho foi o de verifi car se havia diferença quanto à aceitabilidade do sabor do iogurte em vários sabores contendo $85 \%$ de "leite de soja". 


\section{MATERIAL E METODOS}

Foram utilizadas as seguintes matērias-primas:

1. "Leite de soja" marca VITAL, produzido pelo Instituto de Tecnologia de Alimentos (ITAL);

2. Leite pasteurizado tipo B;

3. Polpas de frutas com $60 \%$ de açúcares totais, a saber:

- Polpa de ameixa Carmesin, com $\mathrm{pH}=3,40$

- Polpa de morango com $\mathrm{pH}=3,39$

- Polpa de figo com $\mathrm{pH}=4,78$

- Polpa de abacaxi com $\mathrm{pH}=3,66$

- Polpa de caju com pH $=4,24$

- Polpa de salada de frutas (mamão maduro, banana abacaxi, pera e suco de maracujá) com $\mathrm{ph}=3,60$

- Polpa de pêssego com $\mathrm{pH}=3,80$

- Polpa de goiaba com $\mathrm{pH}=4,16$

4. Suco de caju concentrado com $\mathrm{pH}=3,76$;

5. Suco de maracuja concentrado $\operatorname{com} \mathrm{pH}=2,92$;

6 . Leite de coco concentrado com $\mathrm{pH}=5,71$;

7. Corante Bordeaux S (vermelho), Sanei (verde) e Beta caroteno (amarelo);

8. Leite em pó desnatado;

9. Essências de creme de chantilly imitação leite condensado, abacaxi, ameixa, coco, goiaba, figo, morango, pêssego e banana;

10. Açücar refinado.

Foram experimentados os seguintes tratamentos:

Tratamento A: polpa de abacaxi

Tratamento B: polpa de figo

Tratamento C: polpa de salada de frutas

Tratamento D: polpa de maracujá

Tratamento E: polpa de pêssego

Tratamento $F$ : polpa de morango

Tratamento G: polpa de ameixa

Tratamento H: polpa de caju

Tratamento I: polpa de coco

Tratamento J: polpa de goiaba

As formulações I, II, III, IV, V, VI, VII, VIII, 
IX e $X$, que correspondem ao iogurte com $85 \%$ de "leite de soja" e $15 \%$ de leite de vaca, respectivamente, para os tratamentos A, B, C, D, E, F, G, H, I e J constam na Tabela 1 .

Na Tabela 1, o valor 66,3 para "leite de soja", que aparece em todas as formulações foi encontrado na formulação I, por exemplo, do seguinte modo: (Total - \% polpa de abacaxi - \% açúcar - \% cultura "starter" - \% essência de abacaxi - \% de leite em pó - \% maisena - \% essēncia de creme de chantilly - \% de corante Bordeaux S) $(\%$ "Leite de soja"/Total) $=(100-13,0-5,45$ $1,60-0,07-0,86-0,86-0,08-0,08)(85 / 100)=66,3$.

0 valor 11,7 para leite de vaca, que também aparece em todas as formulações, foi obtido do mesmo modo,sim plesmente substituíndo\% de "leite de soja" por \% de le te de vaca.

O fluxograma do processamento do iogurte de "leite de soja" adicionado de leite de vaca em vários sabores, para as amostras-testes, constam na Figura 1 .

Foi estimada uma quantidade de $1,5 \mathrm{~kg}$ de produto por formulação. Como temos 10 formulações, foi preparado um total de $15 \mathrm{~kg}$ de amostra-teste. Para satisfazer a quantidade de $1,5 \mathrm{~kg}$ de produto na formulação, cada in grediente da formulação foi multiplicado pelo, fator 0,015 .

Em uma cuba de aço inoxidável com capacidade para 25 litros, provida de agitador manual e tampa, foi preparada uma mistura constituída de "leite de soja", leite de vaca, leite em pó e maisena, na quantidade suficiente para as 10 formulações. Para facilitar a incorpora ção de leite em pó e maisena, os mesmos foram previamente reconstituídos em uma porção de leite de vaca e de soja, com o auxilio de um liquidificador.

A cuba com a mistura foi levada à fermenteira aquecida a $85^{\circ} \mathrm{C}$ por 15 minutos, resfriada na própria fer menteira até atingir a temperatura de $42^{\circ} \mathrm{C}$, e inoculada com $1,6 \%$ de uma cultura mista de Streptococcus thermo- 


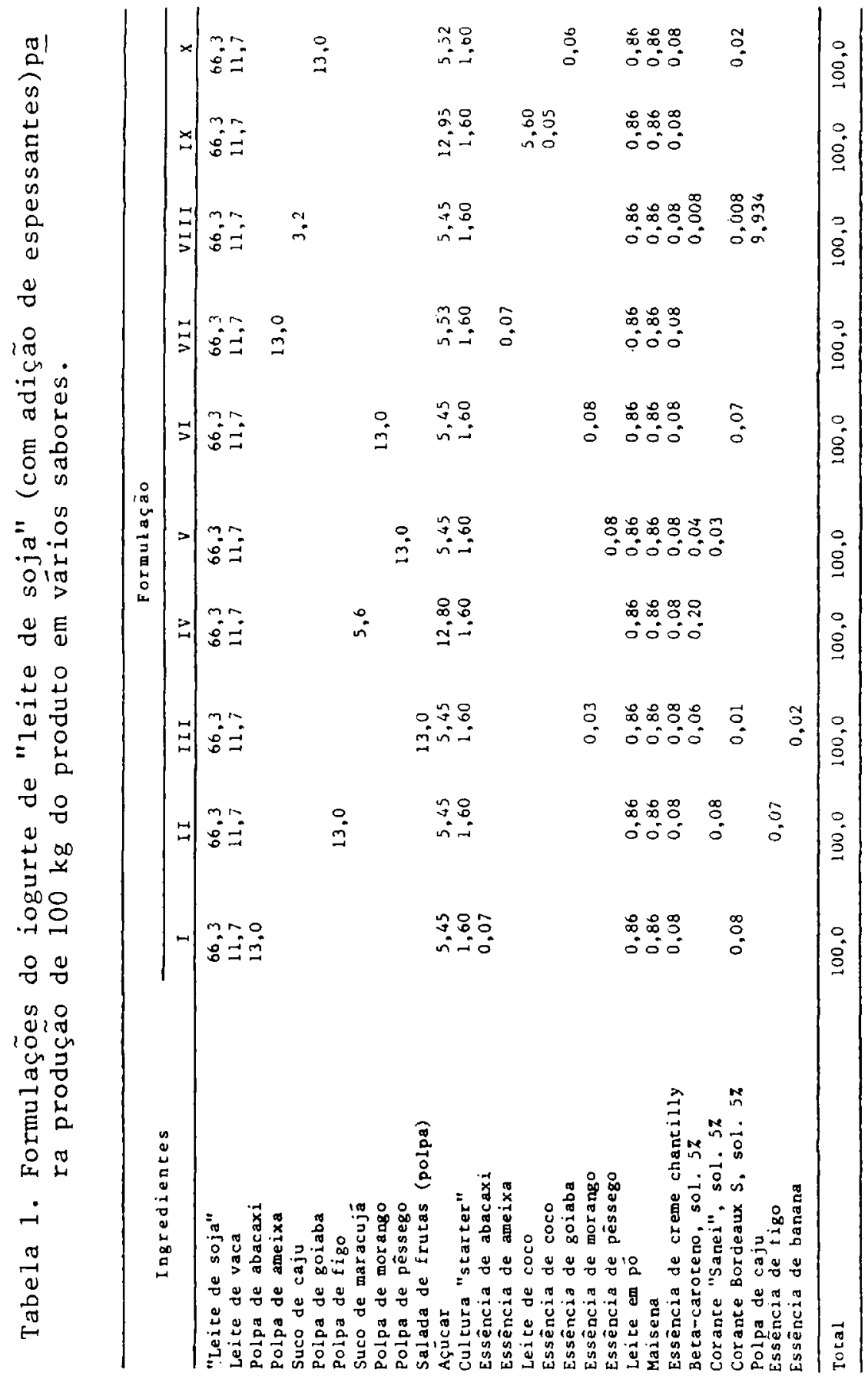


Mistura de "leite de soja" com leite de vaca

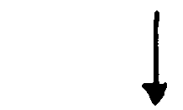

Tratamento térmico

$\left(85^{\circ} \mathrm{C}\right.$ durante 15 minutos)

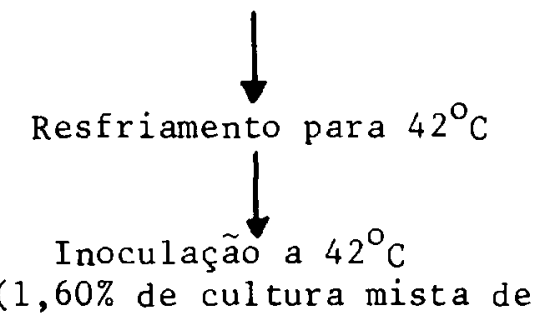

S. thermophilus + L. bulgaricus)

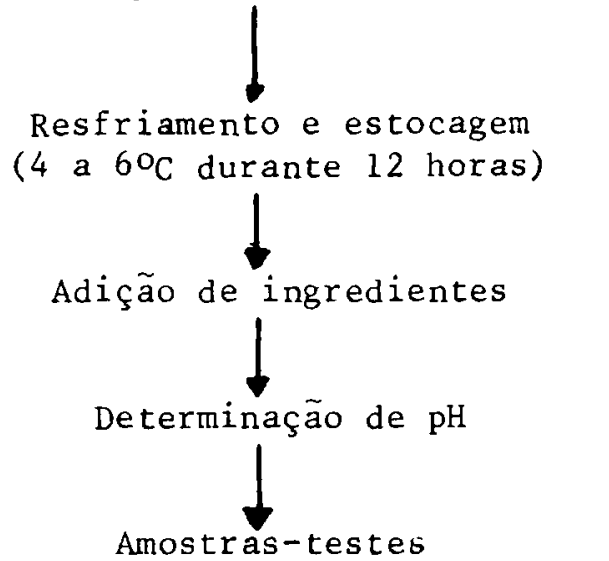

Fig. 1. Fluxograma de processamento do iogurte de "leite de soja" em vārios sabores. 
philus e Lactobacillus bulgaricus (MOON \& REINBOLD 1976) preparada da seguinte forma: O leite desnatado e esterilizado a $121^{\circ} \mathrm{C}$ durante 15 minutos foi resfriado a $37^{\circ} \mathrm{C}$, inoculado com uma cultura-mãe no estado liofilizado, utilizando a proporção de uma ampola de $2 \mathrm{~g}$ de cultura-mãe para 2 litros de leite e incubado a $37^{\circ} \mathrm{C}$ durante 12 horas. Após a incubação, esta cultura ativada foi reativada em série, duas vezes no mesmo meio (leite). Em seguida, ao leite aquecido a $90^{\circ} \mathrm{C}$ por 30 minutos e resfriado a $42^{\circ} \mathrm{C}$, foi inoculado $2 \%$ da cultura reativada e incubado a $42^{\circ} \mathrm{C}$ durante 3 horas, obtendo-se a cultura in termediária. Pelo mesmo processo, a cultura intermediäria deu origem à cultura industrial, empregada na inoculação da mistura e apresentou as seguintes caracteristicas: $\mathrm{pH}=4,2$, acidez total titulável expressa em ácido läctico $=0,80 \mathrm{~g} / 100 \mathrm{~m} /$ e relação $1: 1$ de "cocos e bastonetes". Foi utilizado, portanto, uma cultura pura, mista, desenvolvida em associação e perfeitamente em equilíbrio.

Após a inoculação da mistura, a cuba foi levada pa ra a estufa a $42^{\circ} \mathrm{C}$ onde permaneceu durante 3 horas. Ter= minada a incubação, foram medidos $0 \mathrm{pH}$ e a acidez titulá vel em ácido láctico do coágulo.

o coágulo, após a completa homogeneização com o auxilio de um agitador manual, foi distribuído igualmente entre $10 \mathrm{frascos}$ Erlenmeyer de 2000m 2 . Em seguida, os frascos foram codificados com as letras dos tratamentos e receberam os demais ingredientes: açúcar, essências, polpas de frutas e corantes, de acordo com cada uma das formulações.

Adicionado os ingredientes, o produto foi novamente agitado. Verificada a ausência de granulações e a completa dissolução de todos os ingredientes, for am determinados $O \mathrm{pH}$, extrato seco total em percentagem, açúcares totais e gordura, segundo a A.A.C.C. (1962) e A.O.A.C. (1975).

0 produto assim elaborado foi mantido sob refrigeração entre 4 e $6^{\circ} \mathrm{C}$ até o dia seguinte para a avaliaçao 
organoléptica.

A avaliação organoléptica do produto em dez sabores diferentes foi realizada por 60 provadores não treinados, divididos em 6 grupos de 10 , sendo 3 de manhã e 3 a tarde, segundo o delineamento de blocos incompletos balanceados, tipo quadrado de Youden (Figura 2), repeti do duas vezes, onde blocos = provadores.

os provadores expressaram o quanto gostaram ou desgostaram do sabor do produto em uma escala hedônica de 9 pontos (MORAES, 1981), a saber:

(9) - Gostei muitíssimo

(8) - Gostei muito

(7) - Gostei regularmente

(6) - Gostei ligeiramente

(5) - Indiferente

(4) - Desgostei 1igeiramente

(3) - Desgostei regularmente

(2) - Desgostei muito

(1) - Desgostei muitíssimo

Os números à esquerda de cada grau de apreciação da escala hedōnica, referem-se à quantificação da mesma para fins de anālise estatistica.

As amostras-testes foram servidas simultaneamente aos provadores, segundo o delineamento experimental, em copinhos de poliestireno de $60 \mathrm{~m} /$, que foram identifica dos com números casuais de três dỉgitos. A quantidade servida foi de $30 \mathrm{~m} /$, à temperatura de $10^{\circ} \mathrm{C}$. A luz vermelha foi utilizada para mascarar a diferença de cor entre as amostras. Participaram dos testes aqueles provadores habituados a consumir iogurte e ligados a serviços administrativos, processamentos e laboratórios.

Os dados experimentais (dados organolépticos) foram analisados segundo a técnica estatística da análise da variância através da seguinte estrutura (PIMENTEL GOMES, 1970): 


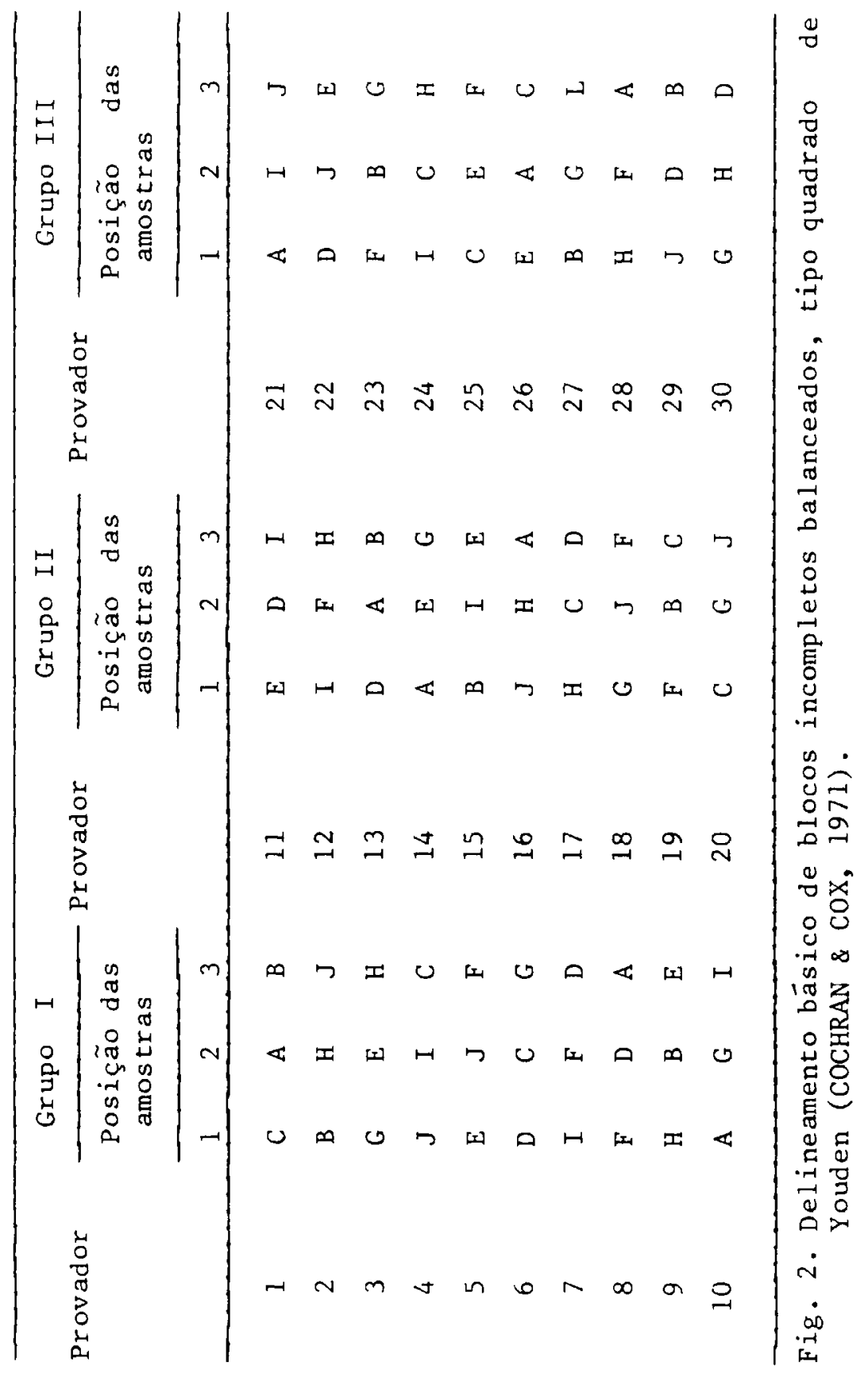


Causa da variação

G.L.

Grupos de provadores

Provadores dentro dos grupos

Posições dentro dos grupos

Tratamentos (ajustados)

Resíduo

5

54

12

9

99

Total

179

0 nivel de erro para os testes estatísticos foi fixado em $5 \%$.

\section{RESULTADOS E DISCUSSÃO}

A composição físico-química do iogurte de "leite de soja" adicionado de leite de vaca em vários sabores, consta na Tabela 2 .

Observando os dados da Tabela 2 , vê-se que a compo sição físico-química do iogurte de "leite de soja" adi= cionado de leite de vaca varia conforme o sabor. 0 prin cipal responsável por esta variação foi o aromatizante $\bar{a}$ base de fruta, utilizado nas formulações.

os graus de apreciação expressos pelos provadores na avaliação do sabor do iogurte de "leite de soja" ałicionado de leite de vaca em vários sabores, constam na Tabela 3 (grupo de manhã) e Tabela 4 (grupo da tarde). Realirando a análise da variância destes dados experimen tais conforme o esquema apresentado, tem-se que o valor da estatistica F para tratamentos $\vec{e} 1,38$; $(0,10<$ $\mathrm{p}<0,25)$ e as médias ajustadas dos mesmos são: $\mathrm{A}=7,3$, $B=5,8, C=7,4, D=6,9, E=6,5, F=6,4, G=6,6$, $H=6,4, I=6,9$ e $J=7,3$.

A não significância do valor da estatística $F$ ao nível de erro de $5 \%$, indica que as médias ajustadas dos tratamentos são estatisticamente indiscerníveis. Por- 


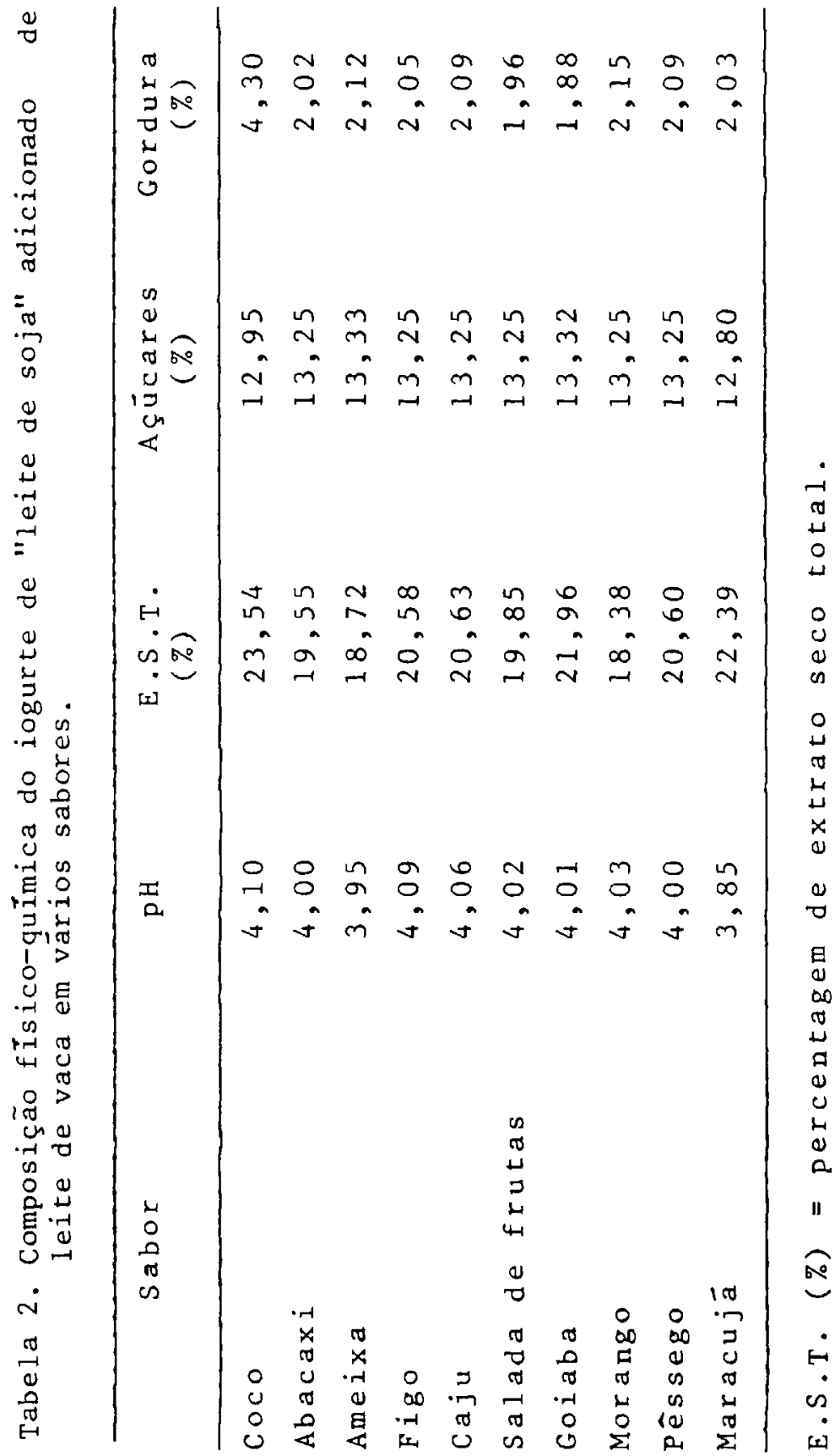



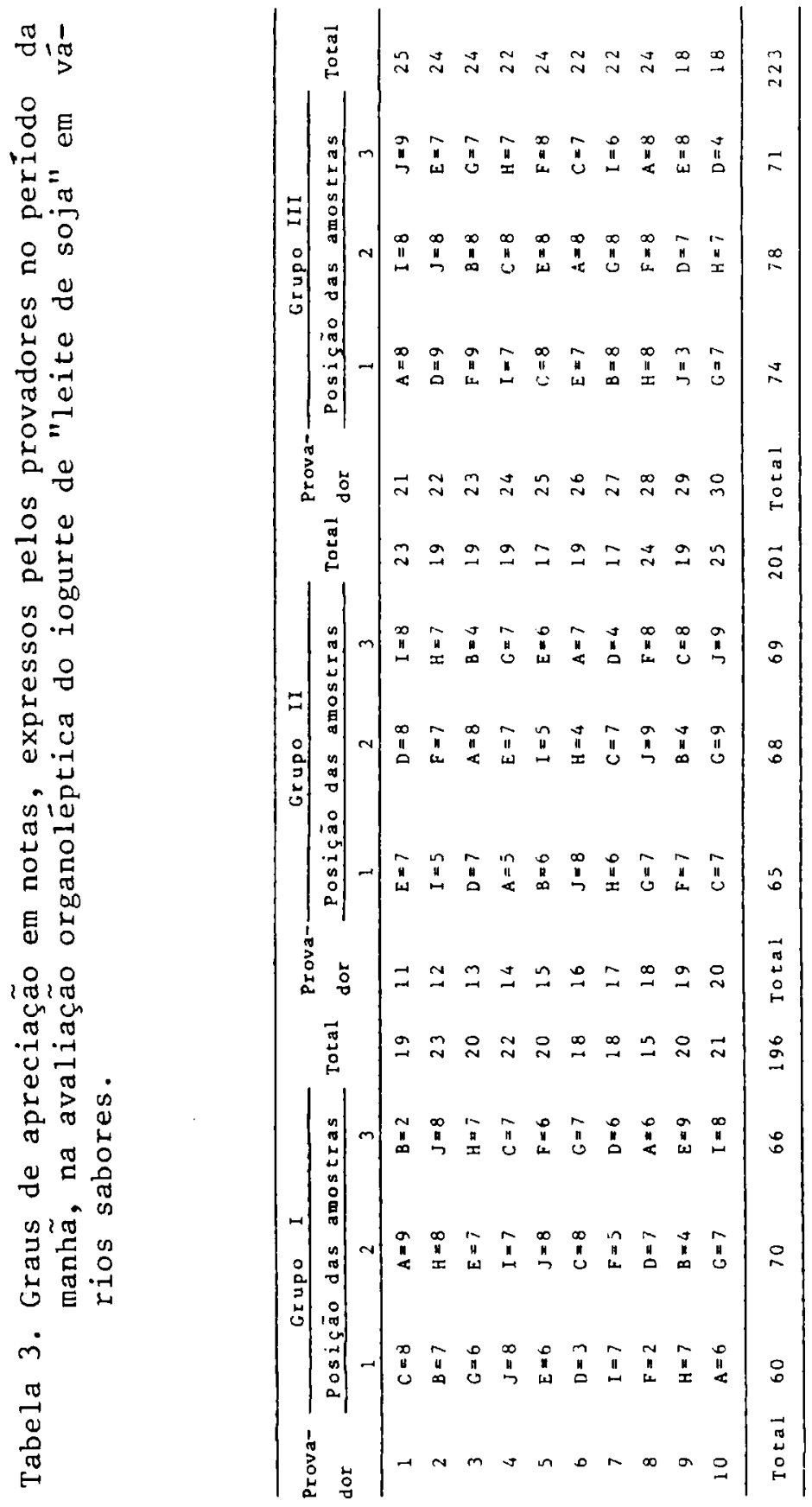


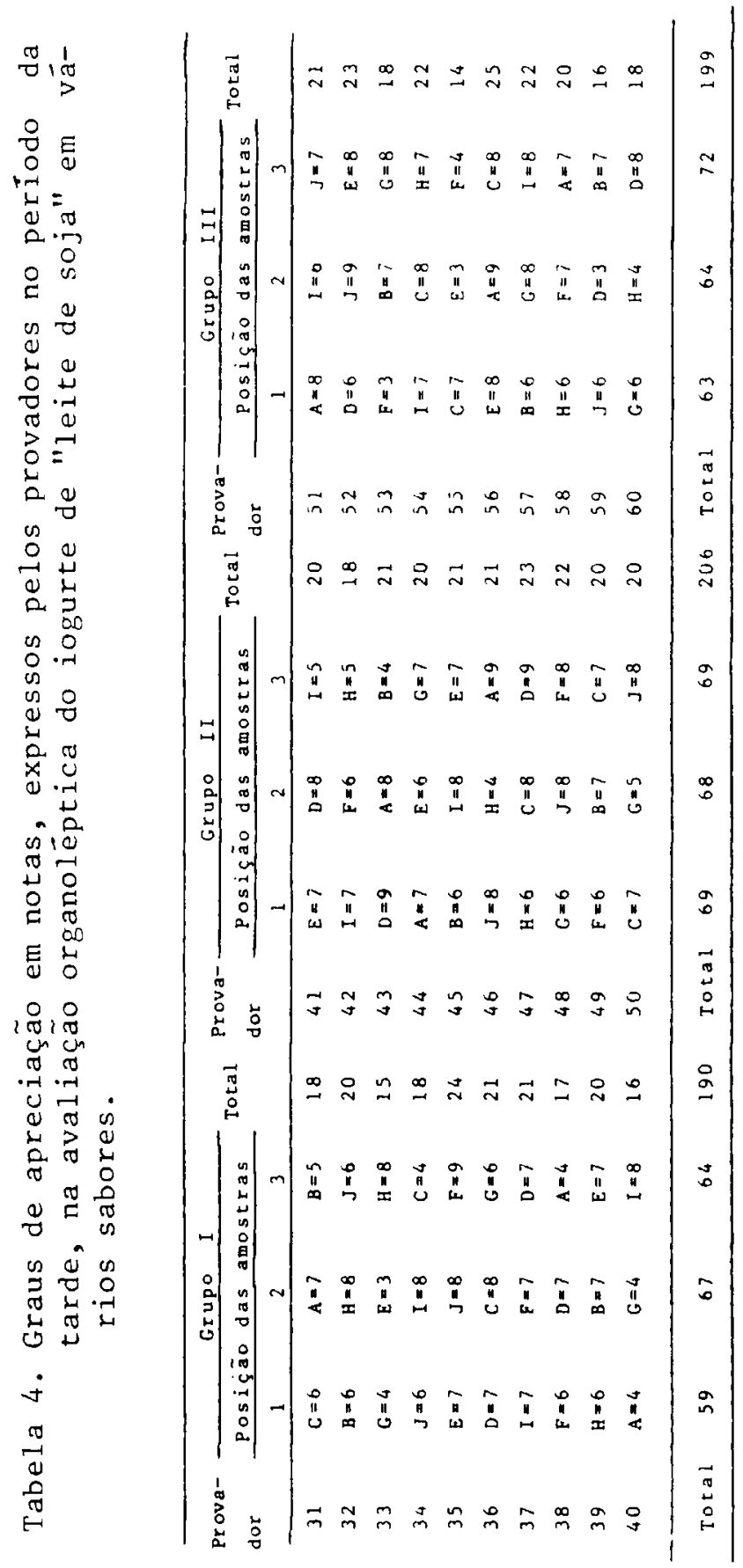


tanto, as diferenças entre médias amostrais podem representar apenas flutuações aleatörias, não servindo de base para afirmar que alguns saborizantes sobressairam mais do que outros na melhoria do sabor do produto.

Referindo-se às médias ajustadas dos tratamentos à escala hedônica, observa-se que os tratamentos A, C, D , E, G, I e J obtiveram médias próximas do valor correspon dente a "gostei regularmente" da escala hedônica e os tratamentos B, F e H do valor correspondente a "gostei ligeiramente". Portanto, todos os tratamentos levaram o sabor do produto na faixa de aceitabilidade da escala he dônica. Devido a não significância do efeito de trata= mentos no sabor do produto, pode-se inferir que todos os tratamentos levaram o produto ao grau de aceitabilida de "gostei regularmente".

\section{CONCLUSÕES}

Com base nos resultados obtidos, pode-se concluir que:

(1) Todos os saborizantes proporcionaram ao iogurte de "leite de soja" adicionado de leite de vaca, sabor aceitável e de grau de aceitabilidade "gostei" regu1armente";

(2) Nenhum saborizante destacou dos demais como melhorador do sabor do produto;

(3) A aceitabilidade do sabor do produto

nos vārios sabores estudados, oferece mais opções ao consumi dor e oportunidade para a indústria trabalhar com as frutas da época;

(4) Em termos de $\mathrm{pH}$, extrato seco total, açúcares totais e gorduras, o produto apresenta uma composição fi sico-química variável. Atribui-se esta variação ao ingrediente à base de fruta, utilizado na formulação. 


\section{REFERENCIAS BIBLIOGRAFICAS}

American Association of Cereal Chemists. Approved methods. 6.ed. St. Paul, 1962.

A.O.A.C. Official methods of analysis of the Association of Official Agricultural Chemists. 12.ed. Washing ton, 1975 .

COCHRAN, W.G. \& CoX, G.M. Diseños experimentales. Mexi co, Editorial Trillas, 1971. 661p.

KANDA, H.; WANG, H.; HESSELTINE, C.W.; WARER, K. Yoghurt production by lactobacillus fermentation of soybean milk. Process Biochemistry, Herts, 2(4): 23-5, 1976.

KOPSIC, T. \& LAURIC, V. Produtos lacteos a partir de la soja. La Alimentacion Latioamericana, Buenos Aires, (144): 44-8, nov./dez. 1978.

MOON, N. \& REINBOLD, D.G. Commensalism and competition in cultures of Lactobacillus bulgaricus and streptococcus thermophilus. Journal. of Milk and Food Technology, Albany, 39(5): 337-41, 1976.

MORAES, M.A.C. Métodos para avaliaşão sensorial de alimentos. Campinas, Fundação Tropical de Pesquisas e Tecnologia de Alimentos, 1981. 62p.

PIMENTEL GOMES, F. Curso de estatistica experimental . São Paulo, Nobe1, 1970. 430p.

PINTHONG, R.; MACRAE, R.; ROTHOWELL, J. The development of a soy based yoghurt. I. Acid production by lactic acid bacteria. II. Sensory evaluation and of volatiles. III. Analysis of oligosaccharides. Journal of Food Technology, Oxford, 15(6): 647-67, 1980.

SOUZA, G. de; OLIVEIRA, A.J. de; SHIROSE, I. Aceitabili dade do sabor do iogurte de "leire de soja" adiciona= do de leite de vaca. Coletânea do ITAL, Campinas, $18(1): 69-75,1988$. 
478 An.ESALQ, Piracicaba, 45(parte 2):463-478, 1988

Recebido para publicação em: 12.09.88

Aprovado para publicação em: 04.01 .89 